\title{
El documental político después de la Guerra Fría ${ }^{1}$
}

\section{Politic Documentary After the Cold War}

\author{
Michael Chanan \\ Roehampton University, London \\ michael@mchanan.net
}

\section{1}

Ya han pasado alrededor de veinte años desde que el documental comenzara a regresar al cine tras el inesperado éxito de filmes independientes como The Thin Blue Line (1988) de Erroll Morris, que trataba sobre un error judicial, y con el documental de Michael Moore Roger \& Me, una realización contra las grandes corporaciones, al año siguiente. Varios ejemplos relevantes del nuevo documental han sido políticos. Junto a filmes sobre deportes, naturaleza, guerra y temas como las familias disfuncionales, se han desarrollado justo a tiempo para beneficiarse de la esfera de circulación ampliada que desde entonces se ha hecho presente a través del video digital e internet, oponiéndose y desafiando explícitamente a la política imperante. El último ejemplo, estrenado mientras escribo estas líneas, es South of the Border de Oliver Stone, un diario de viaje político sobre Latinoamérica en el que Stone usa su influencia hollywoodense para reunirse y hablar de política con presidentes. Comienza con el bastante demonizado Hugo Chávez, pasando después a Evo Morales en Bolivia, Lula en Brasil, los Kirchner en Argentina, Fernando Lugo en Paraguay, Rafael Correa en Ecuador y, en Cuba, Raúl Castro (Stone, por supuesto, ya había hecho Comandante con el hermano mayor Fidel en 2003).

Al rastrear el eje de la izquierda democrática radical a lo largo del continente, la intención expresa de Stone es exponer la burda tergiversación que ocurre en los medios estadounidenses. En uno de los clips que se muestran al inicio del film, Fox News reporta que Chávez es un drogadicto. Supuestamente, él comienza el día consumiendo cocoa (sic) que le es enviada por Morales; más tarde, mientras Stone entrevista a Morales, éste último lo inicia en la costumbre de mascar hojas de coca y aprendemos sus propiedades como un estimulante suave muy preciado en aquellas altitudes. Hay algo de la bufonada característica de Michael

\footnotetext{
${ }^{1}$ Traducción de Rodrigo Jarque del texto "Found Images: Documentary, Film and Social Processes in Portugal". Derechos cedidos por el autor.
} 
Moore en momentos como éstos y Stone admite la admiración que siente por su compatriota norteamericano (Hills, 2006), pero, afortunadamente, mantiene un tono más moderado. South of the Borderse presenta como una serie de encuentros informales, la mayoría de ellos demasiado breves, con un grupo de líderes políticos más o menos radicales que hablan simple, franca y articuladamente sobre la dominación de los Estados Unidos. Estos líderes construyen la imagen de una región en la que la hegemonía del Norte está perdiendo su influencia, cualquiera sean las razones para ello. La eficacia de la cinta se mide fácilmente en los ataques que ha sufrido por parte de los críticos mainstream debido a pequeñas inexactitudes, por sus entrevistas torpes y serviles, o sólo por su ingenuidad política. Pero, como le dijera Tariq Ali, co-escritor del film, a un columnista del New York Times: "No es un secreto que apoyamos el otro lado. Es un documental que expone una opinión." (Rother, 2010) En la opinión del veterano crítico de cine Philip French, la película es "superficial", pero sirve como "un correctivo saludable a la cobertura que se hace de Latinoamérica por parte de la mayoría de los medios norteamericanos, especialmente a la bilis tóxica expelida por Fox News." (French, 2010) Un correctivo que no sólo se necesita en los Estados Unidos.

En todo caso, éste es solamente un tipo de documental político que está rondando hoy en día. ¿Qué podría decirse, por ejemplo, de una película como Darwin's Nightmare (2004), del realizador austríaco Hubert Sauper, quien no suscribe ninguna causa política, pero que nos deja reflexionando sobre la culpabilidad humana? Un retrato visualmente poderoso de la complicidad que existe en la destrucción de la ecología natural en nombre de la libertad económica. La pesadilla en cuestión es el desastre ecológico que se produjo en el Lago Victoria por la introducción de la perca del Nilo, que ha elevado la industria pesquera de Tanzania a sus cifras de exportación más altas, equivalentes al $25 \%$ de su producto externo. El lugar es sumamente simbólico: el lago tropical más grande del mundo, cuna del Nilo, corazón de África, y del que se dice es el lugar del nacimiento de la humanidad. Pero ahora las percas se están comiendo a los otros peces, la cadena alimenticia ha sido interrumpida, más de 200 especies de cíclidos se han desvanecido y los niveles de oxígeno están disminuyendo. Mientras la hambruna amenaza Tanzania, los abundantes peces que se atrapan en el lago resultan ser demasiado caros para su consumo local (a excepción de las cabezas y cadáveres de peces que quedan después del fileteado para su exportación). Esta es una película sin comentarios, con unos pocos intertítulos para dar cierta información. En ella (a diferencia de Stone) el director mantiene un perfil bajo y su voz se escucha ocasionalmente en la banda de sonido. Sauper conoce y filma a los pescadores locales y a los trabajadores de la fábrica, a los niños sin hogar y empleados públicos, a los agentes del Banco Mundial, a ministros africanos, a comisionados de la Unión Europea, a prostitutas tanzaninas y pilotos rusos. A modo de provocación, pregunta 
una y otra vez qué es lo que traen consigo los aviones que se llevan los peces cuando vuelan de vuelta al país. Recibe siempre respuestas evasivas hasta que, finalmente, un piloto ruso admite haber ingresado una o dos veces armas a Angola. Un periodista de investigación local explica cómo el aeropuerto de Mwanza se usa como escala para cargamentos de armas destinadas a zonas de conflicto en otros países. Una metáfora transparente del capitalismo predatorio que, como la perca del Nilo, todo lo devora. Éste es, sin duda, uno de los filmes más profundamente políticos de la década pasada.

De hecho, hay una gran variedad en el estilo y la aproximación a los temas políticos en el nuevo documental. Va desde la agitación anticapitalista airada a modo de defensa de los derechos humanos hasta la melancolía posmoderna. La ecología alterada de los medios públicos tiene un rol en esta diversidad, ya que, pese a que aún controla las audiencias mayoritarias, la televisión, con sus efectos homogeneizantes, ya no es el principal medio de difusión. Esto significa que, en vez de responder a las predilecciones de los ejecutivos de televisión que encomiendan proyectos, el documental puede responder de manera más directa a los grupos a los que va dirigido en particular, con el riesgo de no poder hallar una vía de difusión masiva. Ése fue el caso de McLibel (Reino Unido, 2005, versión original de 1997) de Franny Armstrong, que muestra cómo es posible defenderse en la corte, sin abogados, frente a una demanda interpuesta por una corporación multinacional y ganar. Una historia de David y Goliat que nadie encomendaría; o Injustice (Ken Fero y Tariq Mehmood, Reino Unido, 2001) que trata sobre la muerte de negros bajo custodia de la policía, documental que nadie transmitiría al aire ya que la policía amenazó con una demanda. Filmes como éstos son, a los ojos de los ejecutivos que definen lo que es comercializable o no en la industria, producciones demasiado riesgosas y combativas para ser exhibidas masivamente.

Si el renacer del documental es una señal saludable de un 'regreso a la realidad', entonces, en un mundo dominado por las imágenes fantásticas del cine industrial, la televisión y ahora la red, la realidad trae inevitablemente la política de vuelta a escena. El documental está listo para enfrentar el desafío ya que la política está en sus genes, aunque no siempre se exprese. El modo subyacente al documental es el 'aquí y el ahora'; los sucesos que se desenvuelven frente a la cámara son la evidencia de lo que hay. (Pasolini lo llamaba el "presente histórico", ya que "la realidad vista y oída en su acaecer es siempre en el tiempo presente." 1999, p. 35, cursivas en el original) La cámara del documental apunta directamente a lo social y a lo antropológico y éstos son ámbitos en los que el mundo vivo es controlado, forjado y dominado por el poder y la autoridad, incluyendo aquellos lugares en los que la hegemonía es a menudo invisible, pero palpable pese a todo. Esto también significa que el documental en sí mismo interpela al espectador de manera bastante 
distinta a como lo hace la ficción. La película de ficción, que hereda los paradigmas narrativos decimonónicos de la literatura y el teatro, con sus formas burguesas modificadas por la vocación populista del cine, apela directamente a la vida emocional y sentimental del espectador, a su subjetividad privada, incluso cuando trata de temas públicos, históricos o políticos. El documental, por el contrario, le habla al espectador en cuanto ciudadano, como miembro del colectivo social y participante putativo de la esfera pública, al menos en teoría. La esfera pública es su terreno; eso significa que el documental representa una apuesta a que la esfera pública existe y de que se puede hablarle a través del cine. Como lo ha afirmado Paula Rabinowitz, el cine de ficción del Hollywood clásico ata al espectador a través de personajes que están sicológicamente motivados y de convenciones que realzan su verosimilitud: juntos invitan al espectador a sentirse identificado. Todo el aparato sitúa al espectador como el sujeto de un deseo que es privado e interno. Por contraste, el documental moviliza al espectador como un sujeto social, situado en la historia. Este sujeto claramente también tiene deseos, dice ella, pero la atención se dirige lejos de las manifestaciones sicológicas que "caracterizan a las formas fetichistas de la narrativa [de ficción]", y se lleva a las arenas sociales y políticas de la vida diaria; y más allá, a "los sucesos histórico-mundiales que forjan esas vidas." (Rabinowitz, 1993, p. 129) En pocas palabras, se interpola al espectador de manera diferente en la ficción y en el documental, que hacen diferentes tipos de reclamos acerca de la realidad.

Hay algo importante que añadir: 'político' es un término ambiguo. Por un lado, significa el espacio real de poder y autoridad, antagonismo y conflicto; por otro, indica el terreno ideacional y subjetivo de la ideología (hay críticos de cine que usan el término político aplicado a documentales a manera de insulto, para desecharlos como propaganda. Village Voice se refiere a South of the Border como "propaganda en forma de un película casera." Longworth, 2010) Y por último, indica la función de la esfera pública como el ideal de un espacio de libertad en el que hay debate y deliberación abiertos, un teatro para la contención y discusión. En principio, puede ser crítico del estado, que no existe en ningún lado sin falencias y que en otros lados no existe en absoluto (aunque hoy en día pueda encontrárselo en su formal virtual en la world wide web.) La autoridad, la ideología y la libertad de expresión son todos aspectos de la vida política en su relación al estado con los que el documental siempre debe manejarse. Es muy fácil resbalar entre ellos. Pero también hay un significado ampliado que nos enseña el sicoanálisis, el feminismo y la teoría crítica en el que las instituciones sociales como la familia, la escuela, la iglesia y el lugar de trabajo son también espacios políticos, junto a las distintas asociaciones y organizaciones de la sociedad civil. Esto es muy importante para la práctica del documental ya que éstos, más que conceptos abstractos, son el tipo de espacios a los que la cámara se siente atraída con mayor facilidad (como en los 
filmes paradigmáticos que Frederick Wiseman ha estado realizando desde fines de los '60). De hecho, una de las cosas que el documental puede lograr, al salir a la calle y traspasar puertas cerradas para entrar en lugares semi o completamente privados, es llamar la atención pública a sus temas y preocupaciones a veces con tan sólo sacarlos a la luz. Una película puede tener un efecto político sin militar por una causa, sin hacer campaña por algo ni presentar abiertamente una posición ideológica. En resumen, puede incluso hacerlo sin mencionar la política, si no simplemente al representar juiciosamente y con ojo crítico lo que puede encontrarse en un lugar. Sin envolver sus temas con las tramas narrativas de la ficción, el formato documental es capaz de convertir los estereotipos sociales y los clichés mediáticos en personas reales, con nombre y apellido, viviendo en sus propios lugares y con sus experiencias particulares propias. Aquí nos aproximamos a la cualidad que Gilles Deleuze encontró en el cine de Pierre Perrault y Jean Rouch, en el que los personajes "comienzan a contar historias sin jamás ser ficticios." (1989, p. 150)

Pero dado que la imagen del documental, como nos enseña la semiótica, es tanto índice como ícono, tanto realidad profílmica particular frente a la cámara como símbolo cultural, el resultado es que estas experiencias son siempre oídas y vistas como individuales y características, como ellas mismas y como representaciones de un estado de las cosas en la realidad social. En otras palabras, lo particular se lee casi inevitablemente como lo universal; y he aquí una fuente de problemas. Según Fredric Jameson, el documental funciona en distintos niveles. El primero es el nivel obvio del tema aparente. Después se encuentra el segundo nivel, "en el que lo que no vemos, pero que se encuentra presente todo el tiempo y de lo que la película en realidad trata, es el drama del realizador" en el proceso de hacer el documental. El documentalista es como "un actor que tiene cierta misión, por lo que toda la película puede verse como un tipo de acto dramático en este relato mayor no registrado que este realizador haciendo algo con estos clichés y convenciones; y, por su puesto, después hay otro actor que a menudo no vemos, que son las personas que crean las categorías [...]" En otras palabras, también hay otro nivel, el de los clichés y convenciones, categorías del pensamiento que determinan toda representación, "en el que el film documental, más que un objeto estético por derecho propio, es un objeto en esa narrativa. Y después, estos cuestionamientos sobre lo que uno decide hacer políticamente en una situación como esa terminan siendo parte de la narrativa mayor." (Chanan, 2004, p. 132-133)

2

La libertad estilística en el nuevo documental le permite escapar de las estructuras formuladas y exigidas por la televisión, pero conlleva sus propios peligros, que incluyen la recuperación y la reincorporación por parte de la televisión 
misma. Esto es exactamente lo que ha ocurrido con la narrativa en primera persona introducida por cineastas de vanguardia en los '50, que luego se convertiría en la lingua franca de los documentales independientes de los '80 y que hoy es un 'formato' común tanto para el reportaje televisivo como para lo que se llama odiosamente 'info-entretenimiento' (infotainment). El elemento performático en el documental político en primera persona es responsable de fomentar el narcisismo de un Michael Moore o de un Nick Broomfield, cuyas payasadas y bromas son sin duda entretenidas, pero con resultados que traicionan tanto la impotencia política del investigador como la falta de una cultura política organizada con la cual éstos se puedan conectar. Esto no significa que el documental en primera persona sea políticamente sospechoso per se, como sabemos por los numerosos documentales realizados antes del boom y que estaban enraizados en la política de la identidad en las décadas del '70 y '80. En ellos, la primera persona singular del realizador se escuchaba como una primera persona plural. Moore sólo es el más prominente de los realizadores políticos contemporáneos, porque entrega un fino acto de comedia, fue tomado por los distribuidores internacionales y probó ser un autopromotor brillante. Su último esfuerzo, Capitalism, A Love Story, al igual que sus películas anteriores, tiene como objetivo explícito a toda una serie de instituciones políticas y económicas abrumadoras, pero obedece una regla implícita crucial: como populista de izquierda desafía los intereses de la clase dominante, pero nunca llega a pronunciar palabras atemorizantes como socialismo. El resultado es que consigue grandes presupuestos y emplea a un gran equipo técnico para realizar sus películas, lo que lo sitúa en una categoría propia. Mayoritariamente, sin embargo, el crecimiento del documental partidista independiente se ha facilitado gracias a los reducidos costos del cine digital. Por ejemplo, aún dentro del modo de comedia, The Yes Men, una parodia política en contra de la OMC, fue rodada en varios países diferentes por menos de $\$ 40,000$ (con la ayuda de amigos en los lugares adecuados que pudieron conseguir los viajes gratuitamente). Por supuesto, después uno se debe preguntar qué es lo que estas cifras no incluyen. Si no contamos el costo del equipamiento, no incluimos el pago de renta ni electricidad y no se paga el trabajo de los colaboradores, entonces se consigue la extraordinaria Tarnation (2003), de Jonathan Cauoette, un reflexión sumamente personal sobre la familia disfuncional del realizador, y de la que se nos dice en la publicidad de la película que fue hecha en su propio computador Macintosh con \$218. Los costos de distribución (derechos de compensación, traspaso del video a cine para su exhibición en salas, presupuestos para publicidad y marketing) elevaron esta cifra a $\$ 400,000$, o, en el caso de The Yes Men, agregaron alrededor de \$350,000 más. (Chanan, 2007, p. 9-10) Pero un precio como éste es aún sumamente bajo para el distribuidor cuando se lo compara a los costos de producción de un largometraje de 
bajo presupuesto y presenta una buena posibilidad de hacer negocios más activos que con, digamos, cine arte de países pequeños.

En un debate sobre el fenómeno del documental en la revista neoyorkina independiente de cine Cinéaste en el 2004, un colaborador sugirió "tres razones negativas para la actual popularidad del documental político: Bush, Hollywood y la televisión." Sólo ha cambiado el primer factor. Otro comentó que cuando Morgan Spurlock, el director de otra comedia documental, Super Size Me (2004), le dijo a la audiencia en un festival "Vivimos en un mundo en el que el documental independiente se ha convertido verdaderamente en el último bastión de la libertad de expresión", se ganó una ronda de aplausos a sala llena. (cf. Ibid., p. 29) Esto se refleja también por el crecimiento de un tipo más sobrio de documental político; para permanecer de momento en Estados Unidos, películas como The Corporation (Mark Achbar y Jennifer Abbott, 2003), Outfoxed (Robert Greenwald, 2004) y Unconstitutional (Nonny de la Peña, 2004). En términos estilísticos, estas películas que denuncian abusos del sistema más que al sistema como tal son estéticamente bastante convencionales y normalmente toman la forma de un discurso narrado generalmente sin el elemento performático de la presencia del realizador. Políticamente, tienden a tomar una posición demótica hacia su materia mientras exponen a sus blancos por violaciones a los valores democráticos y la Constitución, y, pese a su estética convencional, permanecen excluidas de la esfera pseudo pública de los grandes medios en los Estados Unidos, ya sea cine, televisión o DVD masivo. Pero el mercado del DVD no es homogéneo y este formato también se ha convertido en el principal medio de distribución alternativa. Internet les permite a los productores forjar un nexo orgánico con una base política y deja que el nuevo documental político en los Estados Unidos obtenga su audiencia por medio de técnicas de marketing virales. La elección de Obama demostró la fuerza política que se puede lograr de esta manera, si bien no se ha mantenido sostenible en el tiempo; internet como medio de organización política a gran escala ha sido, hasta ahora, siempre efímero en sus resultados. A una escala menor, es más eficaz, como el documental.

3.

Si la política se trata del debate social del poder y la autoridad y depende de la coyuntura del momento, el documental político siempre será contingente. Por otro lado, hay diferentes modos en los que la representación en la pantalla puede relacionarse a realidades políticas y hay otros criterios a través de los cuales estas relaciones pueden ser clasificadas. Si ampliamos el espectro, las variedades del documental político se expanden. 
Consideremos Checkpoint (Israel, Yoav Shamir, 2003), un registro estrictamente de observación, filmado durante el transcurso de un año y que trata sobre el régimen de puestos de control que Israel le ha impuesto a los palestinos. No hay comentarios ni se conducen entrevistas, pero la gente se dirige a la cámara espontáneamente. Esto es sumamente importante ya que da una impresión poderosa de cómo la cámara interactúa con una realidad que no puede contener; de este modo, la película se vuelve un poderoso testimonio de la injusticia, con obvias implicaciones políticas implícitas. Un año más tarde, The Power of Nightmares, la serie de televisión de Adam Curtis subtitulada 'The Rise of the Politics of Fear', comprende una trilogía de ensayos fílmicos sobre análisis político, articulados sobre un deslumbrante despliegue de lo que Eisenstein llamó montaje intelectual, debatiendo enfáticamente la hegemonía del estado neoliberal. Y luego está $A B C$ Africa, del 2001, de Abbas Kiarostami, realizado para una agencia de las Naciones Unidas y que trata sobre el Sida en los niños de Uganda: un raro ejemplo de un documental sobre un país tercermundista realizado por un director de otro país tercermundista que cuestiona nuestra percepción, pero que alcanza una limitada exposición mundial.

Si bien cada uno de estos filmes confronta un pedazo de la realidad política, ninguno de ellos hace en lo absoluto una declaración política explícita. Lo que comparten principalmente es un fuerte sentido del realizador como una inteligencia autoral, una presencia determinante. Esto se logra, sin embargo, de distintas maneras. El director puede o no aparecer en escena, pero es probable que su voz aparezca en la banda sonora, como narrador o interlocutor. En Checkpoint escuchamos ocasionalmente una voz en off respondiendo una pregunta realizada ante la cámara. Con excepción de The Power of Nightmares, tenemos la insistencia de la cámara como testigo, el documental como un testimonial, como recopilador de datos. De hecho, en $A B C$ Africa no hay nada más, ya que la película no es más que el diario de viaje de los diez días que Kiarostami viajó con su productor. Por sobre todo, estos son filmes que desafían la ya desacreditada noción de que el documental es capaz de entregar una visión objetiva de la realidad. No abandonan la realidad, el mundo sociohistórico del que buscan ser testigos, a sus propios medios, pero reconocen que la imagen que presentan es al mismo tiempo objetiva y subjetiva, su propio acto de descubrimiento, y no existe contradicción en esta duplicidad. El film resulta ser una presentación objetiva sobre una percepción subjetiva de una realidad objetiva. En palabras de José Carlos Avellar, en el documental la realidad es el coautor del film y no es sólo el personaje el que actúa, si no también la cámara. Esto le crea al documental político propósitos diferentes a los que tenía cuando el género (si esa es la palabra correcta) apareció por primera vez. 
Con excepción del ejemplo de Rusia en la década de 1920, los modelos clásicos del documental político se remontan a la década de 1930, cuando los filmes paradigmáticos de la izquierda eran los de Joris Ivens. Películas como Spanish Earth (1936), y The Four Hundred Million (1939) son por sobre todo poderosos testimonios visuales que llaman a la solidaridad antifascista internacional: contra Franco en España, contra el Japón invasor en China. Apenas narradas por una voz en el soundtrack, en particular en el caso de Spanish Earth, para la que los comentarios estaban escritos y hablados por Ernest Hemingway, las películas emplean música, adecuados efectos de sonido y simples gráficos y leyendas animados. También evitan la banda de sonido sincronizada de la película de ficción, y prefieren la mayor cercanía al mundo que permite la cámara en mano a diferencia del equipamiento de sonido de la época. Películas como éstas sufrieron de restricción para llegar a las organizaciones de solidaridad internacionales y luego fueron eclipsadas por la propaganda de guerra. Con algunas excepciones, no sería si no hasta la década de 1960 que el género se renovó, cuando apareció una nueva generación de equipos de filmación y por fin se hizo posible filmar prácticamente en cualquier lado con sonido sincronizado, cámara en mano e incluso sin luz. En la feliz frase de Mario Ruspoli, uno de los realizadores de la nueva camada que filmó por primera vez de esta manera, por primera vez "el sonido y la imagen caminan juntos del brazo con los personajes en movimiento." (cit. en Chanan, 2007, p. 166) El resultado fue un nuevo movimiento de documental conocido como cinéma vérité, direct cinema y varios otros nombres, cada uno de ellos reflejando un énfasis ligeramente diferente.

En Nueva York, el direct cinema se convirtió en un movimiento para la renovación del reportaje televisivo. Por una curiosa coincidencia, uno de sus primeros ejemplares fue Yanki, No!, de Robert Drew, que fue un South of the Border de su época y que, según la revista Time, fue "diseñado para darle al espectador una mirada de las peligrosas pasiones antiamericanas que crecían a lo largo de Latinoamérica en el vacío de las políticas de los Estados Unidos." (edición del 19 de dic. 1960) Tales filmes son políticos en su materia, pero en términos ideológicos, según un astuto par de historiadores norteamericanos de cine, estaban "hechos a la medida de $[\ldots]$ las susceptibilidades del liberalismo estadounidense y la idea de la prensa como un perro guardián social." (R. Allen y D. Gomery, cit. en Chanan, 2007, p. 178) En París, el cinéma vérité emergió de las preocupaciones de la antropología y la sociología y propuso una manera autoreflexiva de cuestionar la producción de la realidad como representación, que funcionaba en gran medida como una forma de crítica ideológica (de un tipo que no existía en el direct cinema de Nueva York). En Quebec, 'le direct' pertenecía a la 'revolución silenciosa' de los canadienses franceses, cuando una minoría lingüística nacional bajo hegemonía 
anglosajona afirmó su identidad política y cultural propia. En otras palabras, es el intento por parte de un grupo marginado de volver la mirada en otra dirección, incomodando a la geografía imaginaria del centro. "Cuando tratamos de descubrir qué significan los problemas de nuestra cultura," dijo Gilles Groulx de Quebec "nos hacemos conscientes de que nuestra molestia no es artística sino social: podríamos llamarla el intento de expresar al hombre nacido en este país." (cit. por Marcorelles, en Chanan, 2004) Este bien podría ser un latinoamericano hablando.

Hacia el sur, el ambiente político era más hostil en el sentido que había una mayor urgencia, y el resultado fue nada menos que la reinvención del documental político, estimulado por la Revolución Cubana y la creación del 'primer territorio cinematográfico libre' en Latinoamérica, como leía la frase. Esto permite la aparición del tipo de realización cinematográfica militante que Fernando Solanas y Octavio Getino en Argentina llamaron Tercer Cine. Éste no es un término geográfico como Tercer Mundo, porque los tres cines que describen comprenden una geografía virtual por sí solos. El primer cine es el modelo hollywoodense de producción cinematográfica comercial e industrial que también puede encontrarse en lugares como Bollywood. El segundo cine, que en términos generales es el cine de autor o cine arte según el modelo europeo, se difunde incluso más, ya que se convirtió en el modo espontáneo de realización cinematográfica independiente en mercados pequeños tanto en países periféricos como en Europa, Buenos Aires o París. El tercer cine también puede surgir en cualquier lugar: consiste en filmes que el sistema como un todo no puede asimilar por no corresponder a sus necesidades, o que directa y explícitamente proponen combatir el sistema. Pero este tipo de praxis cinematográfica política, de acuerdo a los mismos Solanas y Getino, podría encontrarse en todo el mundo, en donde sea que hubiera personas realizando filmes de oposición que los grandes medios institucionales no pudieran tolerar. Citan el grupo fílmico de la nueva izquierda estadounidense, Newsreel, el cinegiornali del movimiento estudiantil italiano, los filmes de los Etats Généraux du Cinéma Français, y los filmes de los movimientos estudiantiles británicos y japoneses, sin olvidar los experimentos realizados por Chris Marker en Francia al darle cámaras de $8 \mathrm{~mm}$ e instrucción básica de su uso a un grupo de trabajadores. Debido a que el tercer cine floreció en los márgenes, fue capaz de desarrollar un modo sui generis de interpelación política. En Cuba, Julio García Espinosa lo llamó "cine imperfecto", un cine que evitaba la superficie lustrosa del cine comercial para romper la pasividad del espectador, con quien buscaba entablar un diálogo.

En todos estos casos, más que una representación de militancia, la película se concibe como un acto político y una forma de intervención directa; vale decir, el documental político en su forma más autoconsciente. En raras ocasiones se dan las circunstancias en las que la película es superada por las fuerzas políticas de turno 
para convertirse en una expresión directa de esas fuerzas. Si es más probable que esto se dé durante los momentos revolucionarios, cuando todo está cargado con la electricidad política, quizás entonces no sea coincidencia descubrir tres películas de esa índole que retratan la lucha campesina por la tierra durante la década de 1980 en Chile, Portugal y Nicaragua. Más que reportar o explicar, éstas se vuelven una manifestación del proceso que están presenciando. La primera, Expropiación, que data de 1972, fue filmada por Raúl Ruíz, quien ya desplegaba su enorme facilidad para hacer filmaciones improvisadas y muy rápidas, en apenas cuatro días. Realizada con la intención de generar polémica sobre la reforma agraria, revisitando sucesos de la década del '30 para criticar la política legalista y cautelosa del gobierno de la Unidad Popular, el relato histórico se ve superado por el marco político intervencionista del presente. Jameson menciona el segundo ejemplo, Torre Bela de Thomas Harlan, filmada en 1975 en el contexto de un estado portugués en el que los campesinos sin tierra han derrocado al propietario ducal y formado una cooperativa. Con la intención de hacer un film que pudiera exhibirse a grupos similares por todo el país, la cámara se convierte en parte del proceso e incluso, por la forma en la que se comporta, comienza a influenciar los eventos. Lo que lo impresionó, dice Jameson, fue la manera "en la que poco a poco el proceso de hacer el documental tuvo sus efectos en lo que los campesinos hicieron con la propiedad." (Chanan, 2004)

El tercer ejemplo, En tierra de Sandino, muestra cinco años después algo similar en Nicaragua desde la perspectiva del director cubano Jesús Díaz. El director se traslada a una plantación de café en la que el dueño se negaba a pagarles a sus trabajadores. El primer día de su llegada, el dueño no se encontraba. Fingiendo ser parte del equipo de una estación de televisión de Panamá, filmaron una entrevista con el capataz y comenzaron a intentar ganarse la confianza de los trabajadores, a quienes confiesan ser cubanos, esperando no encontrar a un informante entre ellos. Al llegar el dueño al día siguiente, tanto él como su esposa resultaron no ser en absoluto tímidos frente a la cámara y esto arrojó resultados extraordinarios. La cámara fue evidentemente la catalizadora pese a hacer poco más que registrar, tan criteriosamente como le fuera posible, lo que comenzó a desarrollarse. Según Díaz mismo, "se da sólo bajo condiciones especiales que un dueño hable con sus trabajadores y los trabajadores hagan demandas por primera vez en sus vidas. Es un extraordinario momento en la historia. Al registrar una situación como esa, es raro que las personas que filman logren la confianza de ambas partes. También es un momento extraño, porque ... aún no se ha decidido qué parte derrotará a la otra." (cit. en Chanan, 2004, pp. 386-387) Lo que se dio, a medida que los trabajadores lograban ganar confianza en sí mismos y se articulaban y el capataz, el dueño y su esposa se alborotaban y eran finalmente arrinconados, fue una colisión frontal en la que, con la autoridad de la revolución y la cámara como testigo, los menos 
privilegiados fueron conscientes por primera vez de su propia fuerza. Como uno de los campesinos portugueses lo dice en Torre Bela: "Hasta ahora, usábamos la boca para comer. Ahora podemos usarla para hablar."

5

Hacia el sur, en Sao Paulo en el 2009, en la conferencia asociada al festival de documental É Tudo Verdade (Es todo verdad), cuyo nombre es un homenaje al documental brasileño inconcluso de Orson Welles, se nos pidió pensar en el realizador cinematográfico como una entidad política en el contexto del renacimiento del documental político desde los sucesos del 11/9. Esta cuestión implicaba otra más: ver si el viejo vocabulario del cine político de los '60 y '70 era útil todavía. Mientras los asuntos se debatían, se podía encontrar otro nexo con el pasado en las pantallas del festival en diversos filmes que se relacionaban con la recuperación de la historia reciente, incluyendo Corumbiara (Le disparan a los Indios, ¿no es cierto?), en el que Vincent Carelli entrega un examen crítico de las políticas indigenistas de Brasil en los últimos veinte años; Cidadão Boilesen (Ciudadano Boilesen) de Chaim Litewski, que revisita el caso de un empresario danés que fue ejecutado por las guerrillas urbanas a comienzos de los '70 por su relación con los paramilitares; y Regreso a Fortín Olmos de Argentina, en donde Patricio Coll y Jorge Goldenberg regresan a la escena de una cooperativa de leñadores que habían filmado por primera vez en 1966. Todos son ejemplos de lo que los críticos de cine latinoamericanos solían llamar cine rescate, un cine de recuperación histórica. (Muchos filmes similares han sido exhibidos en otros festivales de documental latinoamericanos en los últimos años, pero alcanzan muy poca exposición en Norteamérica, en donde el control de los distribuidores y sus prejuicios no se han debilitado.) Al ver estos filmes se hace patente que el temperamento político ha cambiado y que la vieja militancia revolucionaria ha sido superada, ya que la política no puede volver a ser la misma en ninguna parte después del fin de la Guerra Fría. Sin embargo, no pasa lo mismo con la vieja manera de ver el mundo en términos políticos. Como observó recientemente Eric Hobsbawm, Latinoamérica es un lugar en donde "el viejo idioma puede aún ser hablado" y en donde la gente que habla de socialismo es socialista. (2010, p. 138) Pero esto también significa, y estos filmes dan testimonio de ello, una insistencia en la continuidad del presente con el pasado, precisamente con la convicción de que se trata del mismo mundo y de que los viejos enemigos de la justicia social no son fundamentalmente muy diferentes.

Y si diéramos vuelta la pregunta planteada en Sao Paulo y preguntáramos lo contrario: el espectador como entidad política. Porque ¿qué es el film, en especial el film político, sin su interlocutor? Y la pregunta entonces es cómo caracterizar al espectador político, porque el espectador puede estar ubicado en distintas 
posiciones políticas: en el espacio geográfico, en la temporalidad histórica y en su condición política. Si, efectivamente, el mundo ha cambiado después del 11/9, esto significaría que el espectador ha sido reposicionado históricamente. Pero entonces, también marcaría una diferencia el dónde esté ubicado geográficamente, en el corazón del imperio o bajo ocupación, o en algún lugar como Sao Paulo o, digamos, una aldea de pescadores en Taiwán. Y eso a su vez se relacionaría con las diferencias en la configuración política del país en cuestión y las formas en las que el espectador político es capaz de expresar sus políticas, ya sea a través de documentales políticos o en las calles. (Mientras se llevaba a cabo el festival de documentales en Sao Paulo, Lula se encontraba en Londres asistiendo a la convención del G20. Ahí los anarquistas salieron a las calles poniendo a prueba los límites de la tolerancia democrática, como pudo verse inmediatamente en numerosos videos publicados en la red.)

De hecho, el renacimiento del documental político no ha surgido como una respuesta especial al 11/9 y sus secuelas, si no que representa el malestar más profundo por el capitalismo global después de la Guerra Fría, cuando la Unión Soviética deja de existir y entran en juego nuevas rivalidades internacionales. En esta perspectiva más amplia, el gran quiebre histórico en tiempos recientes fue el colapso del bloque comunista, que trajo como consecuencia el cambio tectónico en el balance geopolítico. Por un lado, este cambio dejó a Estados Unidos como la única súper potencia mundial, y por el otro lado, entre otras cosas, agudizó las contradicciones de las políticas islámicas permitiendo el surgimiento de Al-Qaeda. Una vez más, el efecto de todo esto varía bastante según las diferentes ubicaciones geopolíticas y hace difícil tratar estas distintas posiciones en la misma película al mismo tiempo. Pero ahora hay un factor adicional: el flujo expansivo de las imágenes documentales producido por las convergencias tecnológicas del video e internet. Comenzando más o menos al mismo tiempo que la Unión Soviética implosionó, la world wide web ahora sirve para estimular y multiplicar, de manera desigual y con trancas y barrancas, la circulación de diferentes puntos de vista, a veces de meros clips que no alcanzan a ser filmes y que se yuxtaponen unos sobre otros de manera aleatoria. El paisaje de este dominio del documental expandido se ha convertido en una nueva geografía virtual e ilimitada.

La geopolítica de la globalización tira en direcciones divergentes. Las interconexiones globales se ven fortalecidas y reforzadas, pero también lo están las alianzas locales. Es éste, precisamente, el terreno del cine político como praxis. El resultado de estos cambios se ve en que la geografía virtual del film político, que ya no es cine sino video, se ha visto transformada. Las viejas formas de distribución alternativa fueron eclipsadas por el ocaso de los $16 \mathrm{~mm}$ a fines de la década de 1980, pero el surgimiento del video ha significado una revolución tecnológica tanto en los 
medios de producción como en su difusión. Cada uno de ellos se ha ido volviendo más barato, más accesible y más 'democrático'. El resultado ha sido el reposicionamiento tanto del realizador como del espectador. La alteración más radical, después de la introducción de la cámara de video, se ejemplifica con la aparición a fines de los '80 del video indígena en Brasil (y sus contrapartes en Australia y en otras partes del mundo). En estos casos aislados, el video es producido por videógrafos de las comunidades para sus propios grupos comunitarios, y en él los espectadores se convierten en observadores partícipes en un sentido completamente nuevo. Las cintas no pretenden lograr circulación más allá de las comunidades a las que sirven para lograr el contacto entre ellas. Sin embargo, y dado que el video puede ser producido a muy bajo costo, comienzan a tener una circulación mayor. Lo que aquí sucede es la conquista de un nuevo modo de competencia cultural, ideológica y narrativa por parte de grupos subalternos que ignoran la condición culta de la "ciudad letrada" (como la llama Ángel Rama) y que equivale a una nueva forma de nombrar y expresar la experiencia. Al mismo tiempo, con la computarización, la digitalización e internet, el espectador también sufre un nuevo desplazamiento o dislocación. Puede ser una piquetera en Buenos Aires presenciando sucesos en el barrio vecino a través de una escena representada en un video; o una refugiada palestina durante una oscura y fría noche en una ciudad noreuropea viendo su pueblo natal en un video descargado de internet. La verdad es que, si se sube a internet, el espectador puede ser prácticamente cualquier persona.

Por lo tanto, ¿quién es ahora el espectador político? Y ¿cómo afecta al realizador como entidad política, que siempre está en una dualidad en relación a los individuos retratados y a la audiencia a la que interpela? En los tiempos de los $16 \mathrm{~mm}$, el espectador era siempre un miembro de una audiencia frente a una gran pantalla (aunque no tan grande como en las salas de ensueño). Con el video, esta pantalla se volvió más pequeña y la audiencia se dispersó y atomizó al igual que el espectador de televisión. Entonces llegaron los proyectores de video y se abrieron nuevos espacios de exhibición colectiva para pequeños grupos, incluyendo lugares en los que el acceso era, de lo contrario, limitado o inexistente. El rápido desarrollo de la tecnología del video digital, el DVD, internet y el intercambio de archivos, sirve tanto a las exhibiciones colectivas como caseras, pero sobre todo acelera la circulación de material que sólo se atisba en los medios masivos cuando trata de temas dignos de ser noticia, como la represión a protestas políticas masivas en países como Birmania o Irán. Todo esto sucede con diferentes intensidades y penetración social en diversos países, aunque a veces tiene resultados sorprendentes: la expansión de internet en China, o los teléfonos celulares en África (si bien todavía no gozan de una conexión completa a internet). En todo caso, desde la posición del realizador, más allá de la audiencia local el espectador anónimo está más distante, disperso, socialmente fragmentado y atomizado que nunca. Por supuesto, internet 
también permite la creación de comunidades virtuales que a veces muestran tener un gran potencial para la intervención social; en esos casos el film político pasa a formar parte de este esfuerzo, pero nos impone una serie de nuevas preguntas: ison estos desarrollos algo más que síntomas de la dispersión política?, ¿cuál es su potencial para desafiar al poder establecido?, ¿qué tipo de documental se convertiría en una fuerza política en este proceso?, ¿puede si quiera plantearse de este modo tal pregunta?

6

El surgimiento del video, de los computadores y de internet ha transformado los medios de producción y de diseminación. Poco a poco se han vuelto más baratos, más accesibles y más democráticos, si bien la distribución siempre se da de manera desigual. El resultado de estos cambios ha sido la remodelación de la geografía virtual y cognitiva del documental. La historia en sí misma resulta verse diferente desde que el archivo histórico reaparece en nuevos formatos. Mientras tanto, la pantalla del computador y la conexión a internet borran las distancias incluso con mayor efectividad que la televisión: sólo basta hacer un click sobre otro hipervínculo para estar instantáneamente en otro lugar sin necesidad de ir a ningún lado. Esto no sólo es una metáfora, sino que es la inmediatez virtual de la globalización, una esfera pública paralela que repite, multiplica y amplifica las mismas disparidades y contradicciones que ya existen. Es posible que en el hemisferio norte se descarguen videos largos y cortos sobre el hemisferio sur, y es posible también que un número creciente de festivales de documental en cada continente mantengan un flujo sostenido de documentales provenientes de todo el mundo, pero nunca llegan a nuestros cines o a nuestras pantallas de televisión. Esta exclusión no es accidental sino ideológica y política, independiente de si los filmes desechados lo son explícitamente o no.

Lo que impresiona de los festivales que muestran estos filmes, como Mirada Sur en Tenerife en el 2008, festival dedicado tanto a documentales cortos como largos y que provienen y tratan sobre países del hemisferio sur, es que pocos de éstos son filmes militantes en el sentido antiguo, pero casi todos, de una manera implícita, son decididamente políticos. También impresiona la gran variedad de temas tratados en ellos. Sólo entre los cortos están: futbolistas en Sierra Leona que siguen jugando tras haber perdido una pierna como resultado de la guerra civil (One Goal, Sergi Agusti); granjeros africanos que utilizan una antigua técnica de alimentar gallinas con las hormigas que proliferan en el excremento de las vacas ya que no pueden costear alimento para gallinas (Shit and Chicks, Kees van der Geest); trabajadores chinos que no cuentan con ningún tipo de protección contra los químicos contaminantes con los que trabajan (Living With Shame, Huaqing Jin); la desfiguración de los maniquíes en las vitrinas de Irán por orden de la policía 
religiosa (Rough Cut, Firouzeh Khosrovani). Todos estos ejemplos son cortometrajes simples que hablan desde una posición muy cercana al tema tratado y no son meros comunicados ilustrados, sino intensa comunicación visual: cargados de fuertes imágenes, en su mayoría evitando el comentario (a no ser que sea personal). Y todos ven el mundo como un mundo político, es decir, uno en el que las condiciones de vida están gobernadas por estructuras de poder despóticas y por una autoridad distante que veces se muestra de manera simple y sutil, como en la lata usada por el criador de gallinas en Shit and Chicks en la que claramente se lee 'US AID'.

En resumen, el documental político es un mundo compuesto por una multiplicidad de voces que hablan sobre una multiplicidad de temas a una multiplicidad de audiencias. Sin duda, y pese a la observación de Jameson sobre los niveles y categorías, filmes como los expuestos en Mirada Sur deben responder a las susceptibilidades de las ONG, instituciones de caridad y otras organizaciones que los financian, porque eso es lo que significa ser 'independiente' realmente. Pese a esto, hablamos de un nuevo tipo de espacio de representación polimorfo en el que el lugar del documental político es parte de un proceso más amplio y que no puede ser entendido como una forma de discurso sin este marco mayor. Hay una necesidad imperativa amplia de hablar sobre política a través del cine. Ésta se ve estimulada por nuevas tecnologías que fomentan nuevas formas de realización fílmica participanteobservador. La clave está, como siempre, en la relación del videógrafo con la política alterna y oposicional que surge como respuesta a la aparición de fisuras en las estructuras de poder del estado. Pero el momento político nace en el acto mismo de observar, el momento especial en el que el espectador pasivo se convierte en un espectador activo, lleno de empatía hacia las fantasmagóricas figuras en la pantalla y que oye la pregunta que los niños le hacen a Eduardo Coutinho en la primera escena de Boca de Lixo (1993), "¿Qué es lo que ganas al poner esta cosa en nuestras caras?"

\section{Referencias bibliográficas}

Chanan, Michael, The Politics of Documentary, BFI, 2007

'Talking Film with Fredric Jameson' in Sean Homer and Douglas Kellner, eds., Fredric Jameson: A Critical Reader, Palgrave Macmillan, 2004.

Cuban Cinema, University of Minnesota Press, 2004

Deleuze, Gilles. Cinema 2, The Time-Image, trans. Hugh Tomlinson and Robert Galeta (London: Athlone Press, 1989)

French, Philip (aug. 2010) "South of the Border". The Observer. (obtenido desde www.guardian.co.uk/film/2010/aug/01/south-of-the-border-oliver-stonereview) 
Hills, Aaron (jun. 2006). "Oliver Stone on admiring Hugo Chavez and Michael Moore, being graylisted and doc "South of the Border." IFC.com (obtenido desde http://www.ifc.com/fix/2010/06/oliver-stone-south)

Hobsbawm, Eric, 'Interview', NewLeft Review 61, 2010

Longworth, Karina (jun. 2010). "Oliver Stone and His Presidential Pals Team Up in South of the Border”. The Village Voice. (obtenido desde http://www.villagevoice.com/2010-06-22/film/oliver-stone-and-his-presidentialpals-team-up-in-south-of-the-border/)

Pasolini, Pier Paolo, 'Observations on the Long Take’, Filmwaves no.9, Autumn 1999.

Rabinowitz, Paula. 'Wreckage upon Wreckage: History, Documentary and the Ruins of Memory', History and Theory, Vol.32, No.2 (May, 1993).

Rother, Larry (jun. 2010). “Oliver Stone's Latin America”. The New York Times Movies (obtenido desde http://www.nytimes.com/2010/06/26/movies/26stone. html) 